Check for updates

Cite this: RSC Adv., 2019, 9, 37594

Received 13th October 2019

Accepted 12th November 2019

DOI: 10.1039/c9ra08339a

rsc.li/rsc-advances

\section{One-pot synthesis of CdS/metal-organic framework aerogel composites for efficient visible photocatalytic reduction of aqueous $\mathrm{Cr}(\mathrm{vl}) \uparrow$}

\author{
Haiyan Yang, ${ }^{a}$ Liang Jiang, ${ }^{a}$ Wei Wang, ${ }^{a}$ Zhifang Luo, ${ }^{a}$ Jing Li, ${ }^{b}$ Zijuan He, ${ }^{a}$ Zhiyin Yan ${ }^{a}$ \\ and Jiaqiang Wang (iD) *a
}

\begin{abstract}
Metal-organic framework aerogels (MOAs) embedded with CdS (CdS/MOA(Cr)) synthesized via a facile one-pot solvothermal method have a larger surface area than pristine $\mathrm{MOA}(\mathrm{Cr})$ and the post-synthesized composite. $\mathrm{CdS} / \mathrm{MOA}(\mathrm{Cr})$ exhibited 5 times enhancement in the photocatalytic activity than that of pure $\mathrm{CdS}$ for $\mathrm{Cr}(\mathrm{VI})$ reduction under visible light without adding any sacrificial agent, due to the larger surface area and photosensitazation of $\mathrm{MOA}(\mathrm{Cr})$.
\end{abstract}

$\mathrm{Cr}(\mathrm{vI})$ is a common contaminant in water, and is a potentially carcinogenic contaminant. ${ }^{1}$ In recent years, photocatalytic reduction has been widely regarded as a promising method to remove $\mathrm{Cr}(\mathrm{vI}){ }^{2}$ A number of systems such as those doped with transition metal ions or nonmetallic ions, ${ }^{3}$ or coupled with semiconductors, ${ }^{4}$ have been reported to serve as candidates for this application.

Hybrid CdS-based nanostructures, as a significant class of multicomponent heterogeneous architectures, could bring unexpected properties for improving the potential applications of CdS. ${ }^{16}$ For instance, metal sulphide nanomaterials such as $\mathrm{ZnIn}_{2} \mathrm{~S}_{4}$ nanosheet-coated CdS nanorod heterostructures, $\mathrm{CuFe}_{2} \mathrm{O}_{4} / \mathrm{CdS}$, CdS QD-Decorated Self-Doped $\gamma-\mathrm{Bi}_{2} \mathrm{MoO}_{6}$ and $\mathrm{CdS}-\mathrm{Sn}_{2} \mathrm{~S}_{3}$ dispersed onto reduced graphene oxide are widely used for the photocatalytic reduction of $\mathrm{Cr}(\mathrm{vI})$. $^{4,5}$

On the other hand, metal-organic frameworks (MOFs) have aroused widespread interest due to their porous crystalline frameworks, high surface areas and the feature of light harvesting. ${ }^{6}$ Recent researches have demonstrated the possibility of using MOFs in photocatalytic reduction of aqueous $\mathrm{Cr}(\mathrm{vI})$. For example, MIL-53(Fe) exhibited photocatalytic activity for the reduction of $\mathrm{Cr}(\mathrm{vI})$ in the mixed system(Cr(vi)/dyes). ${ }^{7} \mathrm{NH}_{2}$-UiO66 showed high photocatalytic activity for the reduction of $\mathrm{Cr}(\mathrm{vI})$ in the methanol/Cr(vi) system at $\mathrm{pH} 2 .{ }^{8}$

However, these MOFs are not as effective as that of metal sulphides. We found that embedding of CdS on MOFs could

${ }^{a}$ National Center for International Research on Photoelectric and Energy Materials, Yunnan Provincial Collaborative Innovation Center of Green Chemistry for Lignite Energy, Yunnan Province Engineering Research Center of Photocatalytic Treatment of Industrial Wastewater, School of Chemical Sciences \& Technology, Yunnan University, Kunming 650091, China.E-mail: jqwang@ynu.edu.cn

${ }^{b}$ School of Energy, Yunnan University, Kunming 650091, China

$\dagger$ Electronic supplementary information (ESI) available. See DOI: 10.1039/c9ra08339a significantly increase the photocatalytic efficiency of CdS for visible light-driven hydrogen production. ${ }^{9}$ Recently, CdS, $\operatorname{In}_{2} \mathrm{~S}_{3}$, $\mathrm{SnS}_{2}, \mathrm{Sb}_{2} \mathrm{~S}_{3}$ quantum dots (QDs) into MIL-125(Ti) have shown the photocatalytic activity for reduction of $\mathrm{Cr}(\mathrm{vI})$, due to the photosensitizing effect and the enhanced light harvesting efficiency. ${ }^{10}$ Nevertheless, all these hybrid metal sulphides and MOFs nanostructures were prepared via post-synthesis method. Therefore, these composites would result in the decrease of the surface area compared with pristine MOF.

To improve the physical and chemical properties of MOFs, metal-organic framework aerogels (MOAs) have emerged as a new porous material. MOAs are prepared from metal-organic gels and the liquid in the gels has been replaced with gas by supercritical drying, which achieve high porosity values as MOFs, low density and interconnected networks structure. ${ }^{11}$ MOAs are amorphous and interconnected coherent network structure which is significantly different from MOFs. ${ }^{12}$ Thus, MOAs have exhibited some advantages over MOFs. For example, $\operatorname{MOA}(\mathrm{Cr})$ based on carboxyl porphyrins and MOA(Al) have a fairly better capability in dye adsorption than that of MOFs crystalline material. ${ }^{13} \mathrm{MOA}(\mathrm{Fe})$ showed high efficacy in removal of arsenic in water. ${ }^{14}$ Therefore, it will be a good possibility to apply MOAs and their composites hybrided with CdS as efficient photocatalysts which has not been reported as far as we know.

Herein, we reported a simple and effective strategy to one-pot synthesis of CdS embedded in $\mathrm{MOA}(\mathrm{Cr})(\mathrm{CdS} / \mathrm{MOA}(\mathrm{Cr}))$ composites for the first time. Interestingly, we found that the photocatalytic activity could be significantly improved by embedding CdS in MOA(Cr) than in MIL-100(Cr) and CdS/ MOA(Cr) prepared by post-synthesis method.

$\mathrm{CdS} / \mathrm{MOA}(\mathrm{Cr})$ was synthesized by a facile one-pot solvothermal treatment. The weight ratios of CdS in samples were 3,13 and $20 \%$, respectively, which were labelled as CdS/ $\operatorname{MOA}(\mathrm{Cr})-X$, where $X=3,13$ and $20 \%$. For comparison, CdS/ 
MOA(Cr) was also prepared by post-synthesis method. $\mathrm{MOA}(\mathrm{Cr})$ was synthesized first and then $20 \% \mathrm{CdS}$ was deposited on $\mathrm{MOA}(\mathrm{Cr})$ by solvothermal method, which was named as CdS/ MOA(Cr)-2-post. X-ray diffraction (XRD) measurements (Fig. 1) proved that $\mathrm{MOA}(\mathrm{Cr})$ exhibited weak and broad peaks, which confirmed MOA(Cr) was successfully prepared. The embedded CdS into $\operatorname{MOA}(\mathrm{Cr})$ was also successfully synthesized and the three diffraction peaks were corresponded to cubic phase of CdS. ${ }^{15}$ The average crystallite sizes for the embedded CdS were between 7 to $9 \mathrm{~nm}$ which were calculated using the Scherrer formula for the (111) facet diffraction peak. The XRD pattern was different at the molecular level from MIL-100(Cr) (Fig. S1†). ${ }^{12 b}$

The $\mathrm{N}_{2}$ adsorption-desorption isotherm (Fig. S2 $\dagger$ ) of $\operatorname{MOA}(\mathrm{Cr})$ and $\mathrm{CdS} / \mathrm{MOA}(\mathrm{Cr})$ exhibited typical isotherm of type I having inflection around $P / P_{0}=0.4-0.8$ and type II isotherm was observed on pure CdS. The Brunauer-Emmett-Teller (BET) surface areas, pore volumes and pore sizes of samples are listed in Table 1. The Brunauer-Emmett-Teller (BET) surface area $\left(S_{\mathrm{BET}}\right)$ of $\mathrm{MOA}(\mathrm{Cr})$ is $629.2 \mathrm{~m}^{2} \mathrm{~g}^{-1}$, which also confirms that $\operatorname{MOA}(\mathrm{Cr})$ was properly synthesized. Surprisingly, the $S_{\mathrm{BET}}$ of $\mathrm{CdS} / \mathrm{MOA}(\mathrm{Cr})$ were much higher than that of $\mathrm{MOA}(\mathrm{Cr})$, mainly because the adding anions may affect the coordinative crosslinking of the samples. ${ }^{16}$ The pore volume and pore size were rarely changed after CdS incorporation in $\operatorname{MOA}(\mathrm{Cr})$. While the $S_{\mathrm{BET}}$ and pore values of $\mathrm{CdS} / \mathrm{MOA}(\mathrm{Cr})$-2-post synthesized via post-synthesis methods were much lower than that of $\mathrm{MOA}(\mathrm{Cr})$. In general, the loaded $\mathrm{CdS}$ in $\mathrm{MOA}(\mathrm{Cr})$ by post-synthesis method may block pores of $\mathrm{MOA}(\mathrm{Cr})$. Similarly, the $S_{\mathrm{BET}}$ and pore volume also decrease when CdS loading in MIL-100(Cr). This is attributed to pore blockage by CdS nanoparticles. ${ }^{9}$

The scanning electron microscopy (SEM) images present spongy porous structures with spherical interconnected particles (Fig. 2). CdS/MOA(Cr)-20 show more spongy porous structure than pure $\mathrm{MOA}(\mathrm{Cr})$, which is consistent with that observed from the BET surface areas. In Fig. 2(c), the deposition of CdS is irregular spherical aggregate covered on the surface of $\mathrm{MOA}(\mathrm{Cr})$. The transmission electron microscope (TEM) of CdS/MOA(Cr)20 reveals the fluffy and irregular aggregates (Fig. 2). High resolution TEM reveals a lattice spacing of $0.34 \mathrm{~nm}$ corresponding to the interplanar distance between adjacent (111) crystallographic planes of cubic CdS. Fourier transform infrared (FT-IR) spectra of $\mathrm{CdS} / \mathrm{MOA}(\mathrm{Cr})-20$ and CdS/MIL-100-20 are shown in Fig. 3(a). Strong absorptions at ca. $1620 \mathrm{~cm}^{-1}$

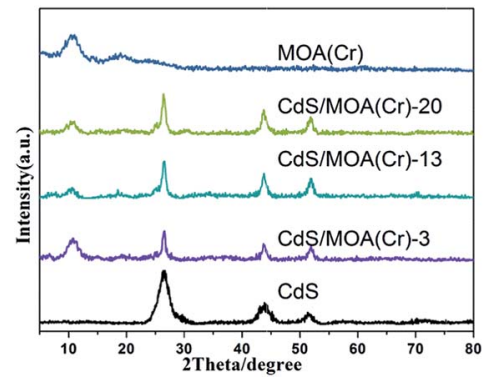

Fig. 1 XRD patterns of the samples.
Table 1 Summary of textural properties of the samples

\begin{tabular}{lcll}
\hline Samples & $S_{\text {BET }}\left(\mathrm{m}^{2} \mathrm{~g}^{-1}\right)$ & $\begin{array}{l}\text { Pore volume } \\
\left(\mathrm{cm}^{3} \mathrm{~g}^{-1}\right)\end{array}$ & $\begin{array}{l}\text { Pore size } \\
(\mathrm{nm})\end{array}$ \\
\hline MOA(Cr) & 629.2 & 0.4 & 3.3 \\
CdS/MOA(Cr)-3 & 821.6 & 0.6 & 3.1 \\
CdS/MOA(Cr)-13 & 829.8 & 0.6 & 3.2 \\
CdS/MOA(Cr)-20 & 714.4 & 0.5 & 3.1 \\
MIL-100 & 1518.8 & 0.9 & 2.4 \\
CdS/MIL-100-20 & 1202.9 & 0.7 & 2.3 \\
CdS/MOA(Cr)-2-post & 312.9 & 0.2 & 2.3 \\
CdS & 131.8 & 0.1 & 5.9 \\
& & &
\end{tabular}

correspond to $\mathrm{C}=\mathrm{C}$ stretching vibrations in phenyl ring and the band observed at about $1727 \mathrm{~cm}^{-1}$ is related to $\mathrm{C}=\mathrm{O}$ stretching vibrations. ${ }^{17}$ The bands observed at $c a .3430 \mathrm{~cm}^{-1}$ correspond to O-H stretching of water molecules. The FT-IR spectra show that coordination bonds are formed between $\mathrm{Cr}^{3+}$ ions and carboxylate groups. ${ }^{17 b, 18}$

Fig. 3(b) and S3(a) $\dagger$ shows the UV-vis diffuse reflectance spectra of the samples. The absorption-band of $\mathrm{MOA}(\mathrm{Cr})$ in the UV region can be assigned to the $\pi-\pi *$ transition of ligands, whereas the absorption-band in the visible region ascribe to the $\mathrm{d}-\mathrm{d}$ spin-allowed transition of the $\mathrm{Cr}^{3+} \cdot{ }^{9,19} \mathrm{MOA}(\mathrm{Cr})$ revealed significant higher absorption in the visible range than that of MIL-100(Cr). It can be attributed to the low temperature of the as-synthesized $\mathrm{MOA}(\mathrm{Cr}){ }^{\mathbf{1 1 d}} \mathrm{CdS} / \mathrm{MOA}(\mathrm{Cr})$ displays mixed absorption feature of pure $\mathrm{CdS}$ and $\mathrm{MOA}(\mathrm{Cr})$, which was consistent with the colour change from deep green to deep yellow-green. Furthermore, the absorption edges of CdS/ $\operatorname{MOA}(\mathrm{Cr})$ showed clear red-shift at the visible light range. The band gaps of the $\mathrm{CdS}, \operatorname{MOA}(\mathrm{Cr})$ and $\mathrm{CdS} / \mathrm{MOA}(\mathrm{Cr})-20$ were calculated from Tauc plot (Fig. S3(b) $\dagger$ ). The band gaps of CdS, $\mathrm{MOA}(\mathrm{Cr})$ and $\mathrm{CdS} / \mathrm{MOA}(\mathrm{Cr})-20$ are estimated as 2.1, 2.0 and $1.7 \mathrm{eV}$, respectively. The result suggests the potential photocatalytic activity of $\mathrm{CdS} / \mathrm{MOA}(\mathrm{Cr})$ under visible-light irradiation.

The photoelectron chemical behaviors of $\mathrm{CdS} / \mathrm{MOA}(\mathrm{Cr})-20$ and CdS/MIL-100-20 were investigated (Fig. S4†). The results showed that $\mathrm{CdS} / \mathrm{MOA}(\mathrm{Cr})-20$ possessed a superior

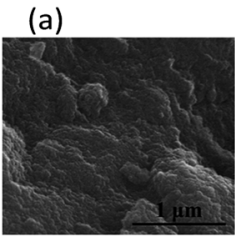

(d)

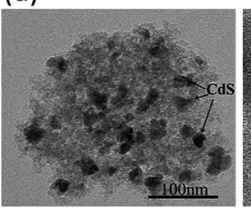

(b)

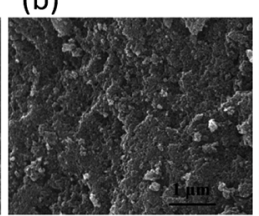

(e)
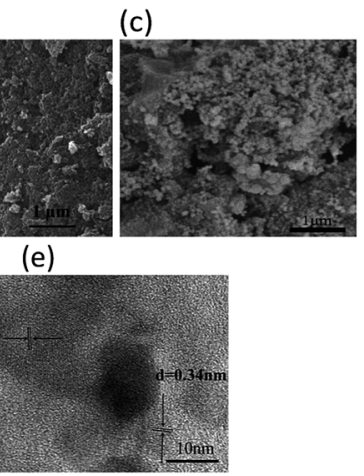

Fig. 2 SEM image of (a) MOA(Cr), (b) CdS/MOA(Cr)-20 and (c) CdS/ MOA(Cr)-2-post. (d) TEM image and (e) HRTEM image of CdS/ $\mathrm{MOA}(\mathrm{Cr})-20$ 
(a)

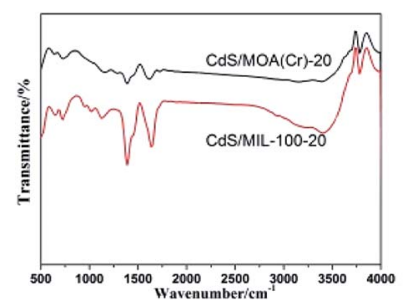

(b)

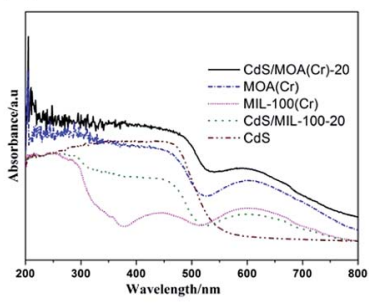

Fig. 3 (a) Fourier transform infrared spectra and (b) UV-vis diffuse reflectance spectra of different photocatalysts.

photocurrent transient response compared with its MOFs counterpart. Then, the samples were evaluated in photocatalytic reduction of $\mathrm{Cr}(\mathrm{vI})$ without any adding sacrificial agent in a quartz reactor under visible light irradiation. The photocatalytic activities results are presented in Fig. 4 and S5. $\dagger$ It is observed that no meaningful activity for photocatalytic reduction of $\mathrm{Cr}(\mathrm{vI})$ was detected in the presence of pure $\mathrm{MOA}(\mathrm{Cr})$ or in the absence of any photocatalyst under visible light irradiation. By contrast, the photocatalytic reduction yields of $\operatorname{Cr}(\mathrm{vI})$ improved with the increase of irradiation time in the presence of CdS/MOA(Cr), MIL-100/CdS and pure CdS. This indicates that the photocatalytic reduction of $\mathrm{Cr}(\mathrm{vI})$ did not occur by $\mathrm{MOA}(\mathrm{Cr})$ alone. The photocatalytic yield of $\mathrm{Cr}(\mathrm{vI})$ of pure $\mathrm{CdS}$ was $20 \%$. When CdS was introduced into $\mathrm{MOA}(\mathrm{Cr})$, the photocatalytic yield was increased notably. After embedding only $3 \mathrm{wt} \%$ of CdS into $\mathrm{MOA}(\mathrm{Cr})$, the photocatalytic yield of $\mathrm{Cr}(\mathrm{VI})$ was increased to $59 \%$. The maximum photocatalytic yield of $\mathrm{Cr}(\mathrm{vI})$ was found at $20 \mathrm{wt} \% \mathrm{CdS}$ ( $\mathrm{ca} .99 \%)$, that was higher than that of CdS/MIL100-20 (ca. 74\%). Furthermore, the XRD patterns, Cr 2p and O 1s spectra of fresh CdS/MOA(Cr)-20 and after used CdS/ MOA(Cr)-20 were displayed in Fig. S5(b)-(d), $\dagger$ respectively. The XRD peaks did not shift after used CdS/MOA(Cr)-20. The binding energy of $\mathrm{Cr}$ and $\mathrm{O}$ were almost unchanged. The results prove no significant change in $\mathrm{CdS} / \mathrm{MOA}(\mathrm{Cr})-20$ after the photocatalytic reaction process.

The photocatalytic reduction rate constant $(k)$ of $\mathrm{Cr}(\mathrm{vI})$ over different samples were calculated by the pseudo-first-order model. The linear plots of $\ln \left(C_{\mathrm{o}} / C\right)$ vs. irradiation time was observed in Fig. S6. $\dagger$ The correlation coefficient $R^{2}$ and corresponding values of $k$ were provided in Table 2 . The rate constants of photocatalytic reduction for $\mathrm{Cr}(\mathrm{vI})$ was calculated to be $5.3 \times 10^{-2} \mathrm{~min}^{-1}$ for $\mathrm{CdS} / \mathrm{MOA}(\mathrm{Cr})-20$, which was

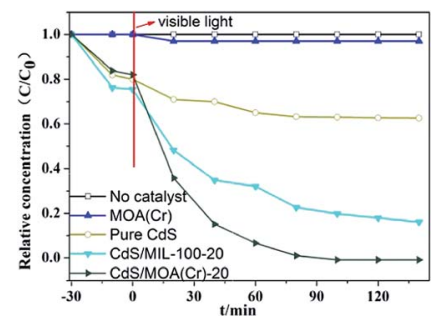

Fig. 4 Photocatalytic activities of photocatalysts for the reduction of $\mathrm{Cr}(\mathrm{vI})$ under visible light.
Table 2 Summary of rate constants of photocatalytic reduction of $\mathrm{Cr}(\mathrm{vI})$ over the samples

\begin{tabular}{lll}
\hline Samples & $\begin{array}{l}\text { Rate contants } \\
\left(\mathrm{min}^{-1}\right)\end{array}$ & $R^{2}$ \\
\hline CdS/MOA(Cr)-3 & $0.6 \times 10^{-2}$ & 0.93 \\
CdS/MOA(Cr)-13 & $1.1 \times 10^{-2}$ & 0.98 \\
CdS/MOA(Cr)-20 & $5.3 \times 10^{-2}$ & 0.95 \\
CdS/MIL-100-20 & $1.4 \times 10^{-2}$ & 0.93 \\
CdS/MOA(Cr)-2-post & $3.6 \times 10^{-2}$ & 0.98
\end{tabular}

approximately 8.8, 4.8, 3.8 and 1.5 times higher than that of CdS/MOA(Cr)-3, CdS/MOA(Cr)-13, CdS/MIL-100-20 and CdS/ $\operatorname{MOA}(\mathrm{Cr})-2$-step, respectively. This could be ascribed to the superior light absorption in the visible range of $\mathrm{MOA}(\mathrm{Cr})$. This highlights the significance of MOA(Cr) based material.

The success in enhancement of the photocatalytic reduction activity of $\mathrm{Cr}(\mathrm{vI})$ by using $\mathrm{CdS} / \mathrm{MOA}(\mathrm{Cr})$ encouraged us to extend this approach to other MOA. MOA(Al) was selected as the model MOA since it is the most-studied MOA. However, under same experimental conditions, CdS modified MOA(Al) exhibited very low activity (ca. 10\%) for photocatalytic reduction of $\mathrm{Cr}(\mathrm{vI})$ (Fig. S5†). This is because that CdS/MOA(Al)-20 did not exhibit any significant absorption in the visible range. The Fig. $\mathrm{S} 4 \uparrow$ shows the photocurrent transient response of CdS/MOA(Al)-20. Under visible light irradiation, the photocurrent transient response of $\mathrm{CdS} / \mathrm{MOA}(\mathrm{Al})-20$ is much lower than that of $\mathrm{CdS} /$ $\operatorname{MOA}(\mathrm{Cr})-20$.

In addition, the valence bands (VBs) of CdS, $\mathrm{MOA}(\mathrm{Cr})$ and $\mathrm{CdS} / \mathrm{MOA}(\mathrm{Cr})-20$ were investigated by XPS. The measured XPS VB values of CdS, MOA(Cr) and $\mathrm{CdS} / \mathrm{MOA}(\mathrm{Cr})-20$ are 1.71, 1.32 and $1.24 \mathrm{eV}$, respectively (Fig. S7†). Correspondingly, the conduction bands (CBs) of CdS, MOA(Cr) and CdS/MOA(Cr)-20 are calculated to be $-0.39,-0.68$ and $-0.46 \mathrm{eV}$, according to their values of band gap energy.

On the basis of the above discussion, a probable mechanism for the photocatalytic reduction is proposed: irradiated light was absorbed mainly by $\mathrm{MOA}(\mathrm{Cr})$ photosensitizer unit and partly by CdS. Under visible light, an excited state of MOA(Cr)* is formed and electrons are transferred from the excited states of MOA(Cr) to the conduction band of CdS. Furthermore, CdS could also be excited by absorbing photons of visible light. The conduction band of CdS is more negative than $\mathrm{Cr}(\mathrm{vI}) / \mathrm{Cr}(\mathrm{III})$ potential $\left(0.51 \mathrm{~V} v s\right.$. NHE) ${ }^{7,20}$ Then the photo-induced electrons accumulated on $\mathrm{CdS}$ can reduce $\mathrm{Cr}(\mathrm{VI})$ to $\mathrm{Cr}(\mathrm{III})$. Meanwhile, water molecules can be oxidized by the holes and the excited state $\mathrm{MOA}(\mathrm{Cr})$ species return to the ground state. ${ }^{21} \mathrm{MOA}(\mathrm{Cr})$ improves the photoinduced electron-hole charge separation and weak the possibility of charge recombination, as well as an ideal host for CdS nanoparticles, which makes it a good photocatalytic reduction activity of $\mathrm{Cr}(\mathrm{vI})$. Additionally, the enhancement of the photocatalytic activity of CdS embedded on $\operatorname{MOA}(\mathrm{Cr})$ can also be attributed to their high surface area and produce more active sites which enhanced photocatalytic activity. 
The photocatalytic activity of $\mathrm{CdS} / \mathrm{MOA}(\mathrm{Cr})$ prepared by postsynthesis method was lower than that of $\mathrm{CdS} / \mathrm{MOA}(\mathrm{Cr})$ prepared by one-pot method. This is due to the CdS nanoparticles just deposited on the surface of $\operatorname{MOA}(\mathrm{Cr})$ but not embedded into MOA(Cr) after post-system method (Fig. S8†) and the specific surface area was decreased. Therefore, when $\mathrm{CdS} / \mathrm{MOA}(\mathrm{Cr})$ prepared by one-pot method as catalyst, the interconnected network structures of could adsorb more light energy onto the catalyst, the aerogel molecules might promote the spread of light and electron transport. ${ }^{\mathbf{1 1 d}, \mathbf{1 2 b}}$

In summary, we have demonstrated for the first time that one-pot synthesis of $\mathrm{CdS} / \mathrm{MOA}(\mathrm{Cr})$ composites significantly increases the photocatalytic reduction activity of $\mathrm{Cr}(\mathrm{vI})$. Through one-pot method, the CdS nanoparticles were embedded into MOA $(\mathrm{Cr})$ and the surface area were increased. The experimental results indicate that $\mathrm{CdS} / \mathrm{MOA}(\mathrm{Cr})$ composites exhibit a better photocatalytic performance than pure CdS and the photocatalytic performance of $\mathrm{CdS} / \mathrm{MOA}(\mathrm{Cr})$ is dependent on the $\operatorname{MOA}(\mathrm{Cr})$ photosensitizer unit which could increase light absorption intensity and charge separation.

\section{Conflicts of interest}

There are no conflicts to declare.

\section{Acknowledgements}

The authors thank the National Natural Science Foundation of China (21573193 and 21603188). The authors also thank the Key Projects for Research and Development of Yunnan Province (2018BA065), Yunnan Applied Basic Research Projects (2016FD009), the Industrialization Cultivation Project (2016CYH04), Scientific Research Fund of Department of Yunnan Education (2017ZZX223), the Program for Innovation Team of Yunnan Province and Key Laboratory of Advanced Materials for Wastewater Treatment of Kunming for financial support. The authors also thank Research Funding of Yunnan Provincial Department of Transportation (2017-438) and Yunnan Water Conservancy Science and Technology Plan of the Water Resources Department of Yunnan province and the Program for Science and Technology Projects of Yunnan Industrial of China Tobacco Industry Co., Ltd. (2015CP03, 2017539200370194, 2016539200340108) for financial support.

\section{Notes and references}

1 (a) B. A. Marinho, R. O. Cristóvão, R. Djellabi, J. M. Loureiro, R. A. R. Boaventura and V. J. P. Vilar, Appl. Catal., B, 2017, 203, 18-30; (b) K. Sridharan, E. Jang and T. J. Park, CrystEngComm, 2013, 15, 8241.

2 C.-C. Wang, X.-D. Du, J. Li, X.-X. Guo, P. Wang and J. Zhang, Appl. Catal., B, 2016, 193, 198-216.

3 Y. Wang, W. Yang, L. Zhang, Y. Hu and X. W. Lou, Nanoscale, 2013, 5, 10864-10867.
4 (a) C. Xue, X. Yan, H. An, H. Li, J. Wei and G. Yang, Appl. Catal., B, 2018, 222, 157-166; (b) N. Nasrallah, M. Kebir, Z. Koudri and M. Trari, J. Hazard. Mater., 2011, 185, 13981404.

5 (a) D. Kandi, S. Martha, A. Thirumurugan and K. M. Parida, ACS Omega, 2017, 2, 9040-9056; (b) G. Zhang, D. Chen, N. Li, Q. Xu, H. Li, J. He and J. Lu, Appl. Catal., B, 2018, 232, 164174.

6 X. Liu, R. Dang, W. Dong, X. Huang, J. Tang, H. Gao and G. Wang, Appl. Catal., B, 2017, 209, 506-513.

7 R. Liang, F. Jing, L. Shen, N. Qin and L. Wu, J. Hazard. Mater., 2015, 287, 364-372.

8 L. Shen, S. Liang, W. Wu, R. Liang and L. Wu, Dalton Trans., 2013, 42, 13649-13657.

9 J. He, Z. Yan, J. Wang, J. Xie, L. Jiang, Y. Shi, F. Yuan, F. Yu and Y. Sun, Chem. Commun., 2013, 49, 6761-6763.

10 H. Wang, X. Yuan, Y. Wu, X. Chen, L. Leng and G. Zeng, RSC $A d v .$, 2015, 5, 32531-32535.

11 (a) M. Saraji and A. Shahvar, Anal. Chim. Acta, 2017, 973, 5158; (b) A. Angulo-Ibáñez, G. Beobide, O. Castillo, A. Luque, S. Pérez-Yáñez and D. Vallejo-Sánchez, Polymers, 2016, 8, 16; (c) S. C. Wei, M. Pan, K. Li, S. Wang, J. Zhang and C. Y. Su, Adv. Mater., 2014, 26, 2072-2077; (d) B. Zhang, J. Zhang, C. Liu, L. Peng, X. Sang, B. Han, X. Ma, T. Luo, X. Tan and G. Yang, Sci. Rep., 2016, 6, 21401.

12 (a) J. Zhang and C.-Y. Su, Coord. Chem. Rev., 2013, 257, 13731408; (b) S. Xiang, L. Li, J. Zhang, X. Tan, H. Cui, J. Shi, Y. Hu, L. Chen, C.-Y. Su and S. L. James, J. Mater. Chem., 2012, 22, 1862-1867.

13 (a) X. Zhao, L. Yuan, Z.-q. Zhang, Y.-s. Wang, Q. Yu and J. Li, Inorg. Chem., 2016, 55, 5287-5296; (b) A. Mahmood, W. Xia, N. Mahmood, Q. Wang and R. Zou, Sci. Rep., 2015, 5, 10556.

14 Z. Gao, J. Sui, X. Xie, X. Li, S. Song, H. Zhang, Y. Hu, Y. Hong, X. Wang, J. Cui and J. Hao, AIChE J., 2018, 64, 3719-3727.

15 X. Yang, Z. Yan, L. Jiang, X. Wang, K. Zheng, Y. Wang, Q. Li and J. Wang, Procedia Environ. Sci., 2013, 18, 572-578.

16 S.-C. Wei, M. Pan, K. Li, S. Wang, J. Zhang and C.-Y. Su, Adv. Mater., 2014, 26, 2072-2077.

17 (a) Y. Hu, Y. Fan, Z. Huang, C. Song and G. Li, Chem. Commun., 2012, 48, 3966; (b) R. S. Andriamitantsoa, W. Dong, H. Gao and G. Wang, New J. Chem., 2017, 41, 1790-1797.

18 J. H. Chen, H. T. Xing, H. X. Guo, G. P. Li, W. Weng and S. R. Hu, J. Hazard. Mater., 2013, 248-249, 285-294.

19 (a) J. He, H. Yang, Y. Chen, Z. Yan, Y. Zeng, Z. Luo, W. Gao and J. Wang, Water, Air, Soil Pollut., 2015, 226; (b) X. Li, Y. Pi, Q. Xia, Z. Li and J. Xiao, Appl. Catal., B, 2016, 191, 192-201.

20 X. Liu, L. Pan, T. Lv, G. Zhu, Z. Sun and C. Sun, Chem. Commun., 2011, 47, 11984-11986.

21 (a) J. Qiu, X. F. Zhang, X. Zhang, Y. Feng, Y. Li, L. Yang, H. Lu and J. Yao, J. Hazard. Mater., 2018, 349, 234-241; (b) H. Zhang, J. Nai, L. Yu and X. W. Lou, Joule, 2017, 1, 77-107. 